\title{
On the Tutorial System of Independent Colleges in Jiangxi Province \\ Xin Chen ${ }^{1}$ and Xiaoyan $\mathrm{Li}^{2}$
}

College of Science and Technology, Jingdezhen Ceramic University, Jindezhen, Jiangxi 333000;

${ }^{2}$ Jingdezhen Ceramic University, Jingdezhen, Jiangxi 333403

\begin{abstract}
Independent colleges in Jiangxi Province implement undergraduate tutorial system, which is a path to explore the establishment of a new relationship between teachers and students while giving full play to professional teachers' role of imparting knowledge and educating people aiming at improving the quality of training talents and promoting the extension of independent colleges' schooling to a more intensive development. The key to the effectiveness of tutorial system lies in the management of tutorial system. Therefore, this paper puts forward some suggestions on the management system of the tutor system in Jiangxi province from the following aspects: defining the position of the tutor, perfecting the operating mechanism, strengthening the construction of the tutor team, perfecting the evaluation mechanism and promoting the typical model.
\end{abstract}

Keywords: Jiangxi province; Independent colleges; Tutorial system; Management countermeasure

\section{浅议江西省独立学院导师制管理对策}

\author{
陈欣 $^{1}$ 李晓燕 $^{2}$
}

（景德镇陶瓷大学科技艺术学院，江西 景德镇 333000; 景德镇陶瓷大学，江西 景德镇 333403）

摘要: 江西省独立学院实施本科生学业导师制, 是探索建立新型师生关系, 充分发挥专业教师教书育人作用 的途径, 旨在提高人才培养的质量, 促进独立学院办学延伸至更为深刻的内涵式发展, 而导师制实施成效的关键 在于导师制的管理。所以，本文从明确导师定位、健全运行机制、加强导师队伍建设、健全考评机制与推广典型 等方面提出了对江西省导师制管理对策的建议。

关键词: 江西省; 独立学院; 导师制; 管理对策

中图分类号：G640 文摘标识码：A

\section{1 完善导师制管理制度是导师制管理的重要前提}

\section{1 完善导师制管理制度}

制度对政策实施的设计是重要的, 江西省独立学院应该以制度的形式着重完善从导师制的整 体设计、导师的选聘、导师的工作过程监督、导师考核及奖惩、导师成果的推广及表彰等环节, 侧重可操作性, 并着实效。

\section{2 明确导师工作职责与要求}

在导师制管理制度中, 具体明确与适时完善导师的工作职责与要求, 让其成为纲领性的导师 行为规则, 引导导师行为, 为江西省独立学院导师制服务。 
明确导师工作职责与要求的最基本的原则就是独立学院一定要明确界定本科生学业导师、班 主任与辅导员的职责范围, 虽然三者的工作职责范围在学生思想道德教育、人生观、价值观教育 方面存在职责范围的重叠现象, 但是学业导师指导内容侧重于学生学习方法与能力、学业规划、 科研训练、职业生涯规划等方面, 尤其重视对学生思想品质、综合能力素质的培养和指导。开展 工作的方式侧重于专业学习与思想政治教育相结合、以个别指导与集体指导相结合。

\section{2 健全运行机制是导师制管理的有力保障}

独立学院导师制就好比汽车, 而导师制的运行机制就好比是汽车的发动机。健全江西省独立 学院导师制的运行机制, 将是其导师制运行效果的有力保障。

\section{1 明确导师制院系二级管理职责}

江西省独立学院导师制推行院系二级管理，应当要对分配制度进行改革，尤其是对导师制管 理的权力分配制度的改革, 以权力下放的形式充分激活导师制发展因素, 提高导师制的内部发展 动力和教育教学活力。明确导师制管理的院系二级权限, 此权力分配制度改革将有利于导师制所 在教学系部管理权限的贯彻落实。

学院一级职责主要侧重于：（1）审核导师所在系部所推荐的导师的是否能满足导师的基本条 件; （2）依据独立学院办学宗旨, 拟定导师工作职责; （3）应对导师工作的过程进行监督管理;

（4）审核并谨慎通过系部对导师的考核结果; （5）协同系部一同做好优秀导师的典型指导成果 的宣传推广工作。

系一级职责主要侧重于：（1）推荐优秀教师至学院导师队伍;（2）依据学院导师工作职责, 督促并监督导师工作完成情况；（3）客观评价并报送导师考核结果；（4）在系部范围内做好优 秀导师典型事迹的报道工作。

\section{2 严把导师选聘关}

在独立学院, 一位良好的本科生学业导师能以其个人所具有的严谨的治学态度、丰富的学识、 和高尚的师德感召学生, 引导学生勤奋学习、献身专业; 也能通过导师勤勤恳恳的工作, 帮助学 生树立适应社会主义的人生观和价值观。因此, 一位良好导师的选聘至关重要。对于导师的选聘, 独立学院应严格把握导师个人的以下六大素养：（1）政治修养;（2）道德修养;（3）思想修养;
（4）作风修养;
（5）文化修养;
(6) 心理修养。

\section{3 建立健全导师工作过程管理监督机制，提高导师制执行力}

导师按照独立学院导师制制度, 明确自身定位便开始开展工作, 而对于独立学院来说, 要提 高导师制的执行力, 就必须对导师的工作过程进行管理监督, 重点让导师了解透彻导师的定位和 职责、了解并掌握导师本身依据学院给予的导师职责是如何开展工作的、掌握导师在工作开展中 遇到什么问题、及时发现导师工作中的偏差并进行纠正、了解导师工作开展后的结果是怎么样的, 对于效果不理想的导师工作积极查找原因, 通过这些过程管理与控制, 以保证导师制目标的有效 
实现。

针对导师制的过程管理, 主要包括导师工作工作过程策划的监督管理、工作过程检测的监督 管理和工作过程改进的监督管理三个部分。

\section{3 加强导师队伍建设是导师制管理的必备条件}

\section{1 加强导师组织领导, 统一导师思想认识}

在实践和认识的辩证关系中，马克思主义哲学十分重视认识对实践的反作用，所以，当导师 一旦被高度统一了思想认识, 那么可以使导师了解、把握独立学院导师制的规律性, 指导导师自 觉地按照独立学院学生的客观规律去从事指导学生的活动; 可以使导师在工作开展之前, 确定既 符合导师自身需要, 又符合学生实际的方案、步骤和措施, 可以对学生的指导活动作出预测和规 划; 可以使导师根据学生指导活动变化了的情况及时调节自己的行动, 指导导师选择实现导师制 目的的最佳行为方式; 可以指导导师将导师制指导学生活动的局部经验上升到一定的理论层面; 还可以使导师通过知道学生活动进一步加深对自身的认识, 并自觉调整自己教师的活动, 以适应 学生需要。更好的为导师制的顺利开展提供最基本的资源保证。

\section{2 强化导师制工作业务学习、培训与经验交流，提高业务素质与水平}

江西省独立学院有必要开展与加强导师制工作的业务学习、培训与经验交流工作, 才会更深 刻地把握导师制教育教学规律, 提升导师队伍的业务素质与水平。

建立导师培训制度，院系二级管理机构定期或不定期的为新聘任的本科生学业导师进行有关 专业的教学计划、课程体系、指导方式方法和语言沟通技巧等方面的培训, 组织学习本科生学业 导师制管理制度、具体实施的相关规定、通知等文件精神, 以提高导师队伍的教育管理指导能力 和导师业务水平。

导师队伍的整体水平和指导效果，并不能仅仅依靠有限的培训、交流，因为这些有限的交流 并不能够马上提升年轻导师们的业务指导水平。而是要依赖于他们通过不断的总结长期的导师指 导实践, 但是, 作为不同年龄、职称、学历结构的导师, 他们在指导学生活动的工作中往往会表 现出各自不同的特点。年轻导师可能更富亲和力, 更能贴近学生的生活和思想, 年长的导师则更 熟悉独立学院教育教学规律, 在专业指导水平上更胜一筹。如果江西省的独立学院能够通过资源 整合、优化的方式，充分利用和发挥不同年龄、不同职称等级、不同学历与经历导师的优势来指 导学生将成为一种创新。就资源整合与优化的方式而言, 还可以充分发挥现有教学团队或科研团 队的作用，对同一团队下的本科生进行指导，或者江西省的独立学院可以考虑建立导师组，共同 指导本科生, 因为这种比较型和不同特点型的导师组合有可能更能在被指导的学生群体中起到较 好的效果。

\section{4 做好导师的绩效评价及反馈工作是导师制可持续发展的重要途径}

\section{1 做好导师的绩效评价, 对导师制工作进行科学化考评}


导师考评是江西省独立学院导师制管理工作的重要方面。健全导师制考评工作机制，提高考 评的水平, 对于树立正确的导师聘任导向、提高导师工作的积极性、推动江西省独立学院导师制 的科学发展, 具有重要意义。

（1）科学界定导师制考核标准，提高考评的针对性。一是加强对导师在指导学生事是否做到 德、能、勤、绩、学的全面考核。细化考评标准, 重点侧重于细化勤、绩指标; 二是合理分配导 师考评指标的权重, 因学生专业的特性问题, 合理分配不同层次、不同学科、不同类型的考评权 重。

（2）改进导师考评办法，提高考评质量。应当坚持导师的平时考核、学期中期考核、年度考 核, 要做到相互补充与相互印证。如果只重视年度考核, 而忽视了平时考核和中期考核, 则弱化 了导师责任的约束和日常监督，会造成平时考核、年度考核相脱节现象，经常性常规性的考核制 度不够健全。应当改变这种状况, 使平时考核、学期中期考核、年度考核衔接配套, 相互贯通。 加强平时考核, 就是为年终考核积累基础性资料。

（3）扩大考核民主化, 增强考核的公信度。对导师的考核, 应当扩大被指导学生的有序参与。 以往他们对导师的考核一般是停留在导师所在系部的二级导师管理机构上, 考评大多是在导师管 理机构内相对封闭地运行, 这样就导致考评主体比较单一, 考评方式是由上而下的, 缺乏被指导 学生的参与和监督, 这很容易导致组织评价与学生效果评价的不一致。要解决这类问题, 关键就 是要扩大被指导学生对考评工作的参与。

同时，增强对导师考核的公开性和透明度。江西省独立学院可以通过学院网站、政务公开等 手段, 发布导师的考核内容、程序和方法, 增加教师、学生对导师考核评价工作的知情度。对导 师的工作目标和工作成绩, 应当在一定范围内定期公开、公示, 让广大教师和学生提前了解导师 履行职责的情况, 让考评小组最后能做出客观公正的评价。

\section{2 做好导师的反馈工作，大力宣传导师典型事迹，推广导师制成果}

榜样的力量可以说是无穷的。学习和宣传先进典型及其事迹, 是中国共产党的优良传统之一, 这也是江西省独立学院开展导师制工作的重要途径与方法。导师典型事迹具有很强的导向作用和 激励作用。独立学院要围绕导师制实施的最终培养应用型人才的目标, 牢牢把握住正确的舆论导 向作用, 科学取一些导师典型事迹、大力宣传导师典型事迹, 以达到推广导师制成果的作用, 激 励广大师生向其看齐, 并以此为经验而提升自身综合素质。

（1）展现优秀导师教师风采, 争做导师模范。江西省独立学院应举办一些优秀导师的学习座 谈会、报告会, 让优秀导师体现科学指导、严谨求实的为学生服务的奋斗精神和关心和爱护的品 质, 可以鼓舞那些正在为导师付出一定贡献的导师, 培养下一批导师模范, 以进一步推动导师制 教育教学改革, 提高人才培养质量。

（2）表彰青春榜样, 激励同学奋发向上。对于导师来说, 其实成功的培养对象一一学生的典 
型事迹更具有榜样的示范和导向作用, 因为他会唤起学生心底的激情与梦想, 激励学生奋发向上。 在导师的引导下, 不乏有一些学生做出过成绩的, 对于江西省独立学院来说, 应当给予这些学生 一些展示优秀学生青春风采的专栏, 宣传报道这些优秀学生在导师的带领下如何积累、沉淀、磨 砺自己的经验和体会的, 使其成为引领、激励广大学生在导师的带领下全面发展、成长成才。

（3）把握导向营造氛围, 推动江西省独立学院和谐发展。明确宣传导师及其优秀学生的定位, 形成鲜明的特色, 并进行合适的宣传, 增大宣传覆盖面和宣传形式的联动, 便会逐渐打造出先进 导师和学生人物宣传的品牌效应, 通过 “优秀导师风采” “优秀学生青春榜样” 等专栏, 以营造 出推动江西省独立学院发展的良好文化氛围, 一方面能体现时代的精神, 增强江西省独立学院的 凝聚力; 另一方面受表彰和宣传的师生又感到荣耀、自豪与激励。能使广大独立学院师生进一步 增强爱校荣校、敬业爱岗的意识, 为推动江西省独立学院的科学发展、和谐发展提供绝佳的精神 动力。

\section{致谢}

基金项目：江西省教育厅高校人文社会科学研究基金项目（GL1365）

\section{Acknowledgement}

Fund Project: Jiangxi Provincial Department of Education universities humanities and social sciences research fund project (GL1365)

\section{参考文献}

[1] 顾倩. 高校实行本科生导师制的成效与对策探索———以西南科技大学法学院本科生导师制为例 [J]. 黄 山学院学报. $2012(04)$.

[2] 肖庆国, 孙钰. 浙江大学城市学院导师制效果研究 [J]. 教育教学论坛. 2012 (S4).

[3] 王志雄. 高校教学导师制之实践路径与运行机制探析 [J]. 教育文化论坛. 2012 (05). 作者简介:

陈欣 (1983-) , 男, 江西永丰人, 景德镇陶瓷大学科技艺术学院讲师, 主要研究方向: 管理学。

李晓燕 (1980-), 女, 内蒙古四子王旗人, 景德镇陶瓷大学计划财务处, 中级会计, 主要研究方向: 管理 学。

\section{References:}

[1] Gu Qian. The effectiveness and Countermeasures of undergraduate tutorial system in Colleges and Universities: a case study of tutorial system for undergraduates of Law School of Southwest University of Science and Technology [J]. Journal of Huangshan University, 2012 (04)

[2] Xiao Qingguo, Sun Yu. Study on the effect of the tutorial system of the City College of Zhejiang University [J]. Education and Teaching Forum.2012 (S4)

[3] Wang Zhixiong. Analysis of the practical path and operating mechanism of the teaching tutorial system in higher education [J]. Educational and Cultural Forum. 2012 (05) 